de la Ciencia: publicó sus obras sin la debida reflexion y meditacion, y asi salieron sin limar; yo $q^{e}$. fui uno de su amigos por diez años seguidos, $q^{\mathrm{c}}$. le regalé plantas, $\mathrm{q}^{\mathrm{e}}$. trabajamos juntos, Herborizamos, y tuvimos muchas conferencias botanicas, le aconsejé $q^{c}$. en [ilegible] $\mathrm{q}^{\mathrm{e}}$.. reiterase sus observaciones acerca de lo publicado y corrigiese muchas descripciones antes $\mathrm{q}^{\mathfrak{c}}$. otros se adelantasen, $\mathrm{y}$ jamas quiso hacerlo; al contrario se exasperava, y me impugnó en varias ocasiones: rompio los lazos de la amistad y se declaró emulo, por no decir rival de mis obras: bastante nos ha dexado $q^{\mathrm{e}}$. corregir. ¡Ojala viviera para bien de la ciencia» ${ }^{5}$.

\section{NOTAS}

1. R. Rodríguez Nozal. Acta Bot. Malacitana 18: 283. 1993; R. Rodríguez Nozal. Llull 17: 403436. 1994; R. Rodríguez Nozal. Acta Bot. Malacitana 23: 193-194. 1998.

2. J. Pavón a C.P. Thunberg. Madrid, 11-VIII-1804; C.P. Thunberg a J. Pavón. Dahan, 6-IX-1804; J. Pavón a C.P. Thunberg, s.l., s.f. (Biblioteca de la Universidad de Uppsala, MS. G5a, X/899)
3. C. Gómez Ortega al Vice-Secretario de la Real Academia de Medicina de Madrid. Madrid, 18IV-1795 (Archivo de la Real Academia de Medicina de Madrid -Arch. R.A.M.-, carpeta IV, leg. 184); "Censura de la obra titulada Disertacion Botanica sobre los generos Tovaria, Atinophyllum, Araucaria y Salmia, como tambien sobre la reunion de algunos que Linneo publicó como distinctos. Por Dn. José Pavon”, mss. A.J. Cavanilles. 2 fols. Madrid, 30-IV-1795 (Arch. R.A.M., carpeta IV, leg. 189).

4. Cf. A.J. Cavanilles. Colección de papeles sobre controversias botánicas... Madrid, 1796.

5. J. Pavón a C.P. Thunberg. Madrid, 11-VIII-1804. Biblioteca de la Universidad de Uppsala, MS G5a, X/899.

Aceptado para su publicación en abril de 2001

Dirección del autor: Departamento de Farmacia y Tecnología Farmacéutica (Cátedra de Historia de la Farmacia y Legislación Farmacéutica). Facultad de Farmacia. Universidad Complutense. 28040Madrid.

\title{
31. TRES NUEVOS MANUSCRITOS DE CUSTODIO DEL CAMPO GARCÍA (1830-1891) SOBRE SUS HERBORIZACIONES EN EL PIRINEO CENTRAL
}

\author{
Antonio GONZÁLEZ BUENO y Daniel SÁNCHEZ-MATA
}

En una ocasión anterior dábamos noticias de los catálogos florísticos del Pirineo Central, conservados entre los fondos de la Sociedad Linneana Matritense, depositados en el Departamento de Biología Vegetal II de la madrileña Facultad de Farmacia'; nos ocupamos ahora de otros tres manuscritos más, éstos destinados a recoger relatos de sus excursiones botánicas por el Pirineo, con la descripción de algunos valles, consejos sobre el modo de herborizar y, en general, advertencias prácticas sobre el mejor modo de 
explorar botánicamente estos territorios.

Los tres manuscritos que reseñamos están escritos en octavillas, sobre papel rayado y posteriormente cosidos; todos están firmados por el autor ${ }^{2}$.

I. Herborizaciones en los Pirineos. Guareña, 8 de noviembre de 1874. 34 págs. Escrito durante una corta estancia en Badajoz, está dedicado a definir las "Cualidades del botánico explorando los Pirineos" y los "Recursos indispensables al explorador botánico." Con un estilo ampuloso, común al resto de sus relatos sobre exploraciones, propone un modelo ideal de herborizador: amabilidad, sencillez, franqueza y valor son, en su opinión, virtudes indispensables para afrontar el estudio de la flora pirenaica. De más interés, por lo que refleja de experiencia personal, es el capítulo dedicado al instrumental necesario para llevar a cabo estas herborizaciones: bastón de madera con cantera y empuñadura de hierro en forma de martillo y azadón, pliegos de papel estraza en una provisional prensa de cartones y cuero, librillo de papel para las plantas de pequeña talla, cuchillo, navaja, lapicero y lupa de mano son algunos de los instrumentos empleados; siguen normas dietéticas, de higiene y la composición de un botiquín para primeros auxilios ${ }^{3}$.

II. Ascensión al Marmorés. 50 págs., precedida de una portadilla con dedicatoria. Relata la subida desde el valle del Pineta, efectuada en el verano de 18694; junto al detallado comentario sobre la toponimia del lugar, se entrelazan noticias sobre las plantas herborizadas, algunas de ellas de interés corológico.
III. Descripción del valle de Pineta. 34 págs. Similar al anterior en su estructura, rehace de manera literaria una excursión por este valle pirenaico.

\section{NOTAS}

1. A. González Bueno \& D. Sánchez-Mata. Acta Bot. Malacitana 23: 194-196. 1998.

2. Archivo del Departamento de Biología Vegetal II (Facultad de Farmacia). Universidad Complutense de Madrid s/c. [Arch. Biol. Veg. II. UCM.] (cf. A. González Bueno. Bol. Soc. Esp. Hist. Farmacia 38(151-152): 347-358. 1987).

3. "Desearía ver figurar en vuestro equipaje un rollo de hilos con dos anchas vendas, un retazo de lienzo con aglutinante y cuatro frasquitos rotulados que contengan alcohol de arnica, balsamo catolico, laudano y alcali volatil." Ms. C. Campo. (Arch. Biol. Veg. II. UCM, s/c).

4. Las ascensión se realizó el 12-VII-1869.

Aceptado para su publicación en abril de 2001

Dirección de los autores: A. González Bueno. Dpto. de Farmacia y Tecnología Farmacéutica. Facultad de Farmacia. Universidad Complutense. 28040 Madrid. D. Sánchez-Mata. Dpto. de Biología Vegetal II. Facultad de Farmacia. Universidad Complutense. 28040 Madrid. 